the response educationally of the still unemancipated section of the nation. Particularly good are his portrait of William Lovett as an oducationist and his definition of the links between the educational and more broadly political aspirations of the Chartists.

The following passage on page 223 reveals both the strength and the weakness of the author's arguments : he quotes from the Northern Star (1848) a rebuke by the workers to those who in their eyes had betrayed them :

"In our day, the Educationists are still what they were in Cobbett's time-the pretended friends, but the real enemies of the people . . . Ah gentlemen, we see through your craft ... . You would educate us, not, as you sometimes pretend, to fit us for the exercise of political rights, but to make us indifferent to those rights. And you call yourselves 'Philosophical Radicals'."

"This uncompromising statement," comments Mr. Simon, "epitomises the reaction of the most advanced section of the working class to the educational tactics of the bourgeoisie." The author's strength lies in his belief in and capacity for using a partial point of view in order to invest a series of historical events with meaning: his weakness lies in a too doctrinaire use of the viewpoint. Such a phrase as 'the educational tactics of the bourgeoisie' implies the ascription of far too conscious and unitary motives to what was a non-homogeneous and changing stratum of society. It merely serves to conceal the more difficult truth that, as Homyakov expressed it, "Only that is conservative which moves forward, and only that is progressive which does not break with the past". Mr. Simon's carefully documented book with its telling illustrations should help perceptive students of English nineteenth-century oducational history to assimilate that paradox. J J Ames L. Henderson

\section{NUCLEAR MAGNETIC RESONANCE}

\section{High-resolution Nuclear Magnetic Resonance}

By J. A. Pople, W. G. Schneider and H. J. Bernstein. (McGraw-Hill Series in Advanced Chemistry.) Pp. xii +501. (London: McGraw-Hill Publishing Company, Ltd., 1959.) 104s. $6 d$.

A $\mathrm{T}$ some stage in the development of almost every specialized physical technique of chemistry there has appeared a text-book which has ultimately becomo recognized as a standard work on the subject. Such books play a very important part in the practice of chemistry because they invariably provide a convenient source from which the underlying principles of the subject to which they pertain can be mastered. It is therefore most fortunate that the technique of high-resolution nuclear magnetic resonanco, which is so obviously destined to be of major importance in chemistry, has acquired a standard text so early in its history, for certainly "High-resolution Nuclear Magnetic Resonance" will admirably fill this role.

This book is the result of a fruitful collaboration of a theoretician and practical spectroscopists, and as such provides a well-balanced account of basic theory, experimental technique, and practical applications. The first part of the book, entitled "Prineiples", deals with theory and its relation to experiment, and includes brief, but sufficient, descriptions of actual spectrometers. An elementary knowledge of quanturn mechanics is necessarily assumed and on this basis the principles of the subject are developed concisely and with considerable clarity. The only serious criticism of Part 1 concerns the generalization made in section 4-8 to the effect that the preferred method of standardizing spectra uses an external reference. Even in 1958 it was more or less recognized that suitable internal references offer considerable advantages.

Part 2 deals with the complete range of applications of high-resolution nuclear magnetic resonance to chemical problems. As the book contains comparatively few references after the first six months of 1958 the real power of proton spectroscopy is not fully indicated. Indeed, it might be argued that the two parts of the book should have been published as separate volumes on the grounds that the contents of Part 2 cannot possibly remain representative of the subject for more than one or two years, and that many private purchasers might have been glad of obtaining Part 1 at a reduced price. Nevertholess, the later chapters of the book contain much which will be of considerable interest and help to both the expert and uninitiated reader.

Such criticisms as have been made above are of minor significance compared with the stimulus which this book is already giving to a rapidly expanding subject. Certainly every worker in the field of nuclear magnetic resonance will need to know and use this book, and those in other disciplines will consult it on numerous occasions. Finally, the authors and publishers are to be congratulated on the uniformity and excellonce of the presentation.

L. M. JACKMAN

\section{PRINCIPLES AND PRACTICE OF TELEVISION ENGINEERING}

Television Engineering

Principles and Practice. By S. W. Amos and D. C. Birkinshaw. (B.B.C. Engineering Training Manuals.) Vol. 1: Fundamentals, Camera Tubes, Television Optics, Electron Optics (written in collaboration with J. L. Bliss). Pp. 302 (1953). 30s. net. Vol. 2 : Video-Frequency Amplification. Pp. $270+5$ plates (1956). 35s. net. Vol. 3: Wave-form Generation. Pp. 226 (1957). 30s. net. Vol. 4: General Circuit Techniques. Pp. 268 (1958). 35s. net. (London: Iliffe and Sons, Ltd.; New York: Philosophical Library.)

THESE four volumes form a comprehensive guide to the principles and practice of television engineering produced by authors who have actively participated in the development of the B.B.C. television services for many years past. The series has been produced from text-books prepared primarily for instruction of the Corporation's own staff, and they are now made available for a wider technical public.

The first volume deals with the fundamental principles of converting a visual scene into electrical signals for transmission to a distant receiver. Considerable space is given to a description of the various types of television camera tubes, and a discussion of the principles of the transmission of light by lenses and mirrors, and of the analogous problems encountered in electron optics. Volume 2 is devoter to video-frequoncy amplification at both high and 